\title{
Effects of Mn addition and related Mn-containing dispersoids on the hot deformation behavior of 6082 aluminum alloys
}

\author{
Xiaoming Qian ${ }^{1}$, Nick Parson ${ }^{2}$, X.-Grant Chen ${ }^{1, *}$ \\ ${ }^{1}$ Department of applied sciences, University of Quebec at Chicoutimi, \\ Saguenay, QC, Canada, G7H 2B1 \\ (*Corresponding author: xgrant_chen@uqac.ca (X.-Grant Chen)) \\ ${ }^{2}$ Arvida Research and Development Centre, Rio Tinto, \\ Saguenay QC, Canada, G7S 4K8
}

\begin{abstract}
The hot deformation behaviors of 6082 aluminum alloys containing different $\mathrm{Mn}$ contents $(0.05-1.0 \mathrm{wt} \%)$ were systematically investigated by uniaxial compression tests in a temperature range of $400-550{ }^{\circ} \mathrm{C}$ and strain rate range of $0.001-1 \mathrm{~s}^{-1}$. Prior to the hot deformation, a low-temperature homogenization $\left(450^{\circ} \mathrm{C}\right.$ for $\left.6 \mathrm{~h}\right)$ was carried out on direct-chill cast billets to promote the precipitation of Mn-containing dispersoids. The large numbers of dispersoids in the Mn-containing alloys yielded significantly increased high-temperature flow stresses, compared to that of the base alloy without dispersoids. The material constants and activation energies for hot deformation were determined using the hyperbolic-sine constitutive equation and experimental peak flow stress data. The activation energy increased from $191 \mathrm{~kJ} / \mathrm{mol}$ for the base alloy to 286 $\mathrm{kJ} / \mathrm{mol}$ for the alloy with $0.5 \%$ of $\mathrm{Mn}$. With further increase in Mn content, the activation energy increased only moderately to $315 \mathrm{~kJ} / \mathrm{mol}$ for the alloy with $1.0 \%$ of $\mathrm{Mn}$. The influences of the Mn content and deformation conditions on the dynamic recovery and recrystallization were quantitatively analyzed. The precipitation of dispersoids in the Mn-containing alloys promoted the retardation of the dynamic recovery and inhibition of the recrystallization owing to their strong pinning effect on the dislocation movement and subgrain migration.
\end{abstract}

Keywords: 6082 aluminum alloy; Mn addition; Dispersoids; Hot deformation; Activation energy; Dynamic recovery and recrystallization

\section{Introduction}

In recent years, driven by the automotive and aerospace industries, the demand for aluminum alloys operating at elevated temperatures has increased. Dispersoid strengthening is one of the most important hardening mechanisms in aluminum alloys for elevated temperature applications, which has led to an increasing academic and 
industrial interest for the development of dispersoid-strengthened aluminum alloys [14]. Recent studies have demonstrated that the addition of $\mathrm{Mn}$ or its combinations with other transition elements can introduce a high number of thermally stable nano-sized dispersoids, such as $\alpha-\mathrm{Al}(\mathrm{MnFe}) \mathrm{Si}$ in $3 \mathrm{xxx}$ alloys [2,5,6], $\mathrm{Al}_{6}(\mathrm{MnFe})$ in 5xxx [7,8], and $\alpha-\mathrm{Al}(\mathrm{MnFe}) \mathrm{Si}$ in Al-Si foundry alloys $[3,9,10]$, providing remarkable increases in strengths at room temperature and particularly at elevated temperatures. For $\mathrm{Al}-\mathrm{Mg}-\mathrm{Si}$ 6xxx alloys, $\mathrm{Mn}$ is an important alloying element to increase the strength and control the grain structure [11]. Among the other 6xxx alloys, the 6082 alloys have a high potential for the formation of dispersoids owing to their high contents of $\mathrm{Mn}$ and $\mathrm{Si}$, which are supersaturated in the as-cast state and follow the decomposition of the supersaturated solid solution during the heat treatment to precipitate a considerable number of dispersoids [12,13]. The addition of $\mathrm{Mn}$ in 6082 alloys could significantly enhance the precipitation of $\alpha-\mathrm{Al}(\mathrm{MnFe}) \mathrm{Si}$ dispersoids during the homogenization $[13,14]$. In a recent study by $\mathrm{Li}[15]$, it is found that $\alpha-\mathrm{Al}(\mathrm{FeMn}) \mathrm{Si}$ dispersoids in 6082 alloys started to precipitate at $350{ }^{\circ} \mathrm{C}$ and reached the highest number density at 400 $450{ }^{\circ} \mathrm{C}$. At temperatures higher than $500{ }^{\circ} \mathrm{C}$, the dispersoids coarsened and the number density sharply decreased with time.

The production of aluminum wrought alloys involves many steps, starting mainly with direct chill (DC) casting of billets/ingots and processing with a homogenization heat treatment, followed by hot deformation processes, such as extrusion, rolling, or forging. The high-temperature flow stress is one of the most significant factors for the hot deformation regime owing to its substantial impacts on the required deformation load and kinetics of the metallurgical transformation [16]. The high-temperature flow stress was closely related to the alloy chemistry, homogenization heat treatment history, and microstructure [14,16,17]. In general, Al-Mg-Si 6082 alloys prior to the hot deformation are subjected to a high-temperature homogenization treatment (550 $580{ }^{\circ} \mathrm{C}$ ) [14], where dispersoids could precipitate during the heating. The sizes and number density of the dispersoids have an important role in determining the hightemperature flow stress, retardation of the dynamic recovery (DRV), and inhibition of the recrystallization. However, after such high-temperature homogenization treatments, the Mn-containing dispersoids in the 6082 alloys were coarsened and dissolved, leaving a limited number of dispersoids in the aluminum matrix [12-14]. Several studies have been carried out to investigate the effects of $\mathrm{Zr}$ and $\mathrm{V}$ and related dispersoids on the flow stress behavior and inhibition of the dynamic recrystallization (DRX) in 7xxx alloys [18-20]. However, a systematic investigation of the effects of $\mathrm{Mn}$ and related Mn-containing dispersoids on the hot deformation behaviors and deformed microstructures of $\mathrm{Al}-\mathrm{Mg}-\mathrm{Si}$ 6xxx alloys has not been carried out.

Different types of constitutive equations have been applied to analyze and predict the hot deformation behaviors of aluminum alloys. Among the many equations and 
models, the hyperbolic-sine Arrhenius-type equation proposed by Sellars and McTegart [21] is widely used for the constitutive analysis over wide ranges of temperature and strain rate. Using this constitutive equation, the activation energy, $Q$, for hot deformation could be derived based on a series of flow stress data. The $Q$ values were often used to compare the difficulty degrees of plastic deformation of different aluminum alloys $[19,20,22]$. Recent studies demonstrated that $Q$ of an alloy was not constant, but might vary with deformation conditions (mainly temperature and strain rate) [23-25]. The changes in hot deformation flow stress and activation energy are closely related to the balance between the dynamic work hardening and dynamic softening under a specific hot deformation condition [19]. DRV and DRX are the main softening mechanisms during the deformation at a high temperature [26-28]. The DRV is associated with changes in density and distribution of line defects, while DRX occurs through a progressive transformation of subgrains to newly formed grains as well as grain boundary migration $[19,20]$. The effects of $\mathrm{Zr}$-containing dispersoids $\left(\mathrm{Al}_{3} \mathrm{Zr}\right)$ and V-containing dispersoids $\left(\mathrm{Al}_{11} \mathrm{~V}\right)$ on the DRV and DRX in $7 \mathrm{xxx}$ alloys have been thoroughly studied [18-20]. The softening mechanism of 7050 alloys shifted from DRV to DRX with a decrease in Zener-Hollomon parameter $(Z)[19,29]$. However, the influences of Mn-containing dispersoids $(\alpha-\mathrm{Al}(\mathrm{MnFe}) \mathrm{Si})$ on the deformed microstructures of 6xxx alloys owing to the DRV and DRX are still not well understood.

In this study, we focused on the effects of Mn and related Mn-containing dispersoids on the hot deformation behavior of 6082 aluminum alloy. In contrast to the usual hightemperature homogenization, a low-temperature homogenization at $450{ }^{\circ} \mathrm{C}$ for $6 \mathrm{~h}$ was applied to DC cast billets to promote the maximum precipitation of Mn-containing dispersoids prior to the hot deformation. The influences of different Mn contents ( $0.05-$ $1.0 \mathrm{wt} \%)$ on the high-temperature flow stresses as a function of the deformation temperature and strain rate were studied. Using the hyperbolic-sine constitutive equation, the material constants and activation energies for hot deformation were calculated based on flow stress data. The microstructural evolution of the alloy during the hot deformation was investigated to understand the effects of the dispersoids on the DRV and DRX.

\section{Experimental methods}

Experiments were carried out on four 6082 alloys without and with different $\mathrm{Mn}$ contents of $0.5-1.0 \%$ (denoted as the base, $0.5 \mathrm{Mn}, 0.75 \mathrm{Mn}$, and $1 \mathrm{Mn}$ alloys). The materials were obtained from DC cast billets with diameters of $101 \mathrm{~mm}$, provided by the Arvida Research and Development Center of Rio Tinto in Saguenay, Quebec. The chemical compositions of the alloys analyzed by optical emission spectroscopy are presented in Table 1. To promote the precipitation of a large number of dispersoids, homogenization at a relatively low temperature of $450{ }^{\circ} \mathrm{C}$ for $6 \mathrm{~h}$ at a heating rate of 
$100{ }^{\circ} \mathrm{C} / \mathrm{h}$, followed by water quenching at room temperature, were applied to the DC cast billets prior to the hot deformation, aiming to evaluate mainly the dispersoid effects on the hot deformation behaviors of the 6082 alloys.

Table 1 Chemical compositions (wt.\%) of the experimental alloys.

\begin{tabular}{llllll}
\hline Alloys & $\mathrm{Mg}$ & $\mathrm{Si}$ & $\mathrm{Fe}$ & $\mathrm{Mn}$ & $\mathrm{Al}$ \\
\hline Base & 0.79 & 1 & 0.18 & $\mathbf{0 . 0 5}$ & Bal. \\
$\mathbf{0 . 5 M n}$ & 0.83 & 1.01 & 0.22 & $\mathbf{0 . 5 0}$ & Bal. \\
$\mathbf{0 . 7 5 M n}$ & 0.84 & 1.02 & 0.23 & $\mathbf{0 . 7 2}$ & Bal. \\
$\mathbf{1 M n}$ & 0.81 & 1.02 & 0.24 & $\mathbf{0 . 9 9}$ & Bal. \\
\hline
\end{tabular}

After the homogenization, cylindrical specimens having diameters of $10 \mathrm{~mm}$ and lengths of $15 \mathrm{~mm}$ were machined for uniaxial hot compression tests, performed in a Gleeble 3800 thermomechanical testing unit. The specimens were heated at a rate of $2{ }^{\circ} \mathrm{C} / \mathrm{s}$ to the desired temperature and held for $180 \mathrm{~s}$ to ensure a homogeneous temperature distribution. The deformation temperatures were $400,450,500$, and $550{ }^{\circ} \mathrm{C}$, while the strain rates were $1,0.1,0.01$, and $0.001 \mathrm{~s}^{-1}$. The specimens were deformed to a total true strain of 0.75 and then immediately water-quenched to retain the deformed microstructures at the specific temperature and strain rate.

To analyze the microstructures of the as-homogenized materials, the polished samples were etched with a $0.5 \% \mathrm{HF}$ solution for $40 \mathrm{~s}$ and investigated using optical microscopy (Nikon, Eclipse ME600) and scanning electron microscopy (SEM, JEOL-6480LV). All deformed samples were sectioned parallel to the compression axis along the centerline and metallographically prepared. An electron back-scattered diffraction (EBSD) analysis was carried out in the SEM to investigate the grain structures under different deformation conditions. In the EBSD image analysis, the boundaries of grains and subgrains were defined as low-, medium-, and high-angle boundaries with misorientation angles of $2-5^{\circ}, 6-15^{\circ}$, and larger than $15^{\circ}$, respectively. Misorientation angles below $2^{\circ}$ were not considered to avoid the noises caused by the sample surface and polishing conditions. The step size of the EBSD analysis was set to $0.5 \mu \mathrm{m}$. Besides, the subgrain size of the deformed samples was measured using the line intercept method $[20,22]$, and the subgrian was defined as the grains separated by the low- and mediumangle boundaries. To ensure the statistical reliability, more than 100 subgrains were measured in each deformed sample. To observe the Mn-containing dispersoids in detail, transmission electron microscopy (TEM, JEM-2100) operated at $200 \mathrm{kV}$ was employed. TEM thin foils were prepared by a twin-jet polishing unit using a solution of $30 \%$ nitric acid and $70 \%$ methanol at $15 \mathrm{~V}$ and $-20{ }^{\circ} \mathrm{C}$. 


\section{Results}

\subsection{Microstructures after the heat treatment}

The microstructures of the base and $0.75 \mathrm{Mn}$ alloys after the heat treatment at $450{ }^{\circ} \mathrm{C}$ for $6 \mathrm{~h}$ are shown in Fig. 1. The microstructures were composed of aluminum dendrite cells (Al matrix), Fe-rich intermetallics (white) distributed along the dendrite boundaries, and primary $\mathrm{Mg}_{2} \mathrm{Si}$ particles (black) mostly colocated with the Fe-rich intermetallics. The intermetallics exhibited a plate-like morphology ( $\beta$-AlFeSi, Fig. 1a) in the base alloy and Chinese-script-like morphology ( $\alpha$-Al(FeMn)Si, Fig. 1b) in the $0.75 \mathrm{Mn}$ alloy. As the microstructures of the three Mn-containing alloys $(0.5 \mathrm{Mn}$, $0.75 \mathrm{Mn}$, and $1 \mathrm{Mn}$ ) after the heat treatment were similar, only the typical microstructure of the $0.75 \mathrm{Mn}$ alloy is presented.
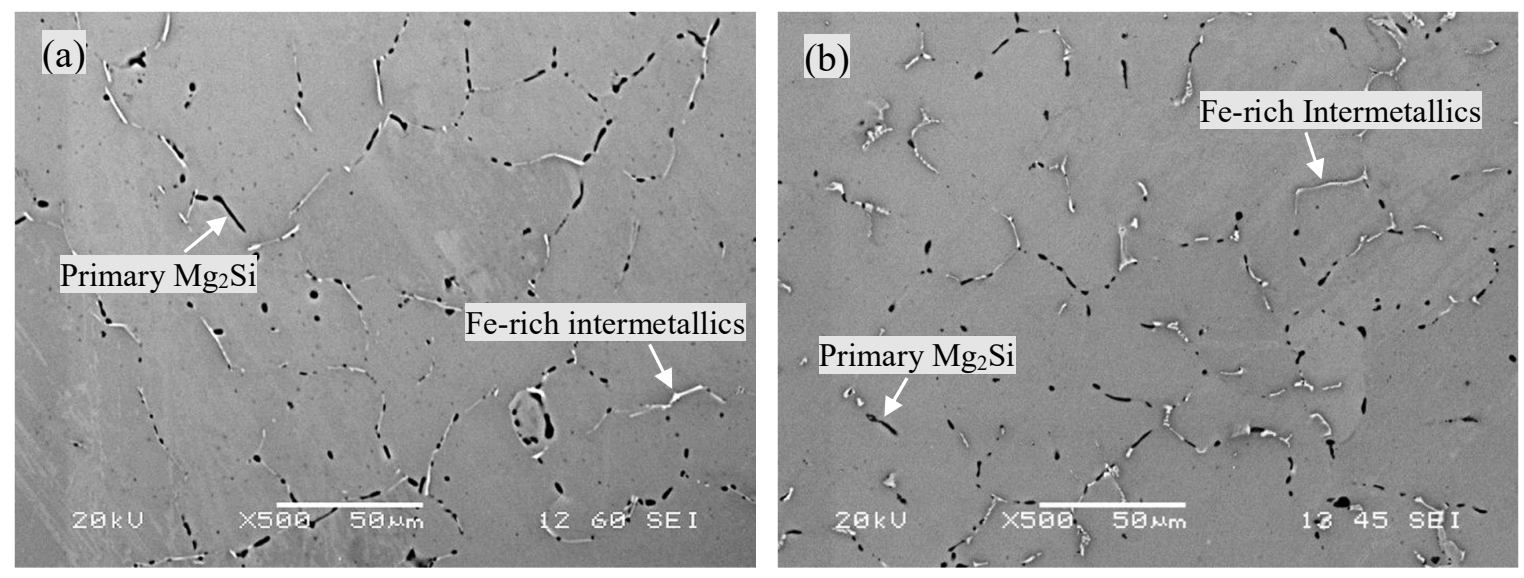

Fig. 1 Microstructures of (a) base alloy and (b) $0.75 \mathrm{Mn}$ alloy after the heat treatment of $450{ }^{\circ} \mathrm{C}$ for $6 \mathrm{~h}$.

After the etching with the $0.5 \% \mathrm{HF}$, the dispersoids can be clearly revealed in the three Mn-containing alloys (Fig. 2). In the base alloy, no change in the aluminum matrix was observed, indicating the absence of dispersoid formation (Fig. 2a). On the contrary, dispersoid zones emerged inside the aluminum dendrite cells and large numbers of dispersoids precipitated in the three Mn-containing alloys (as an example, the $0.75 \mathrm{Mn}$ alloy is shown in Fig. $2 \mathrm{~b}$ and c). However, in the interdendritic regions containing the Fe-rich intermetallics and primary $\mathrm{Mg}_{2} \mathrm{Si}$, almost no dispersoids were observed (Fig. 2c), which are thus defined as particle-free zones (PFZs). 


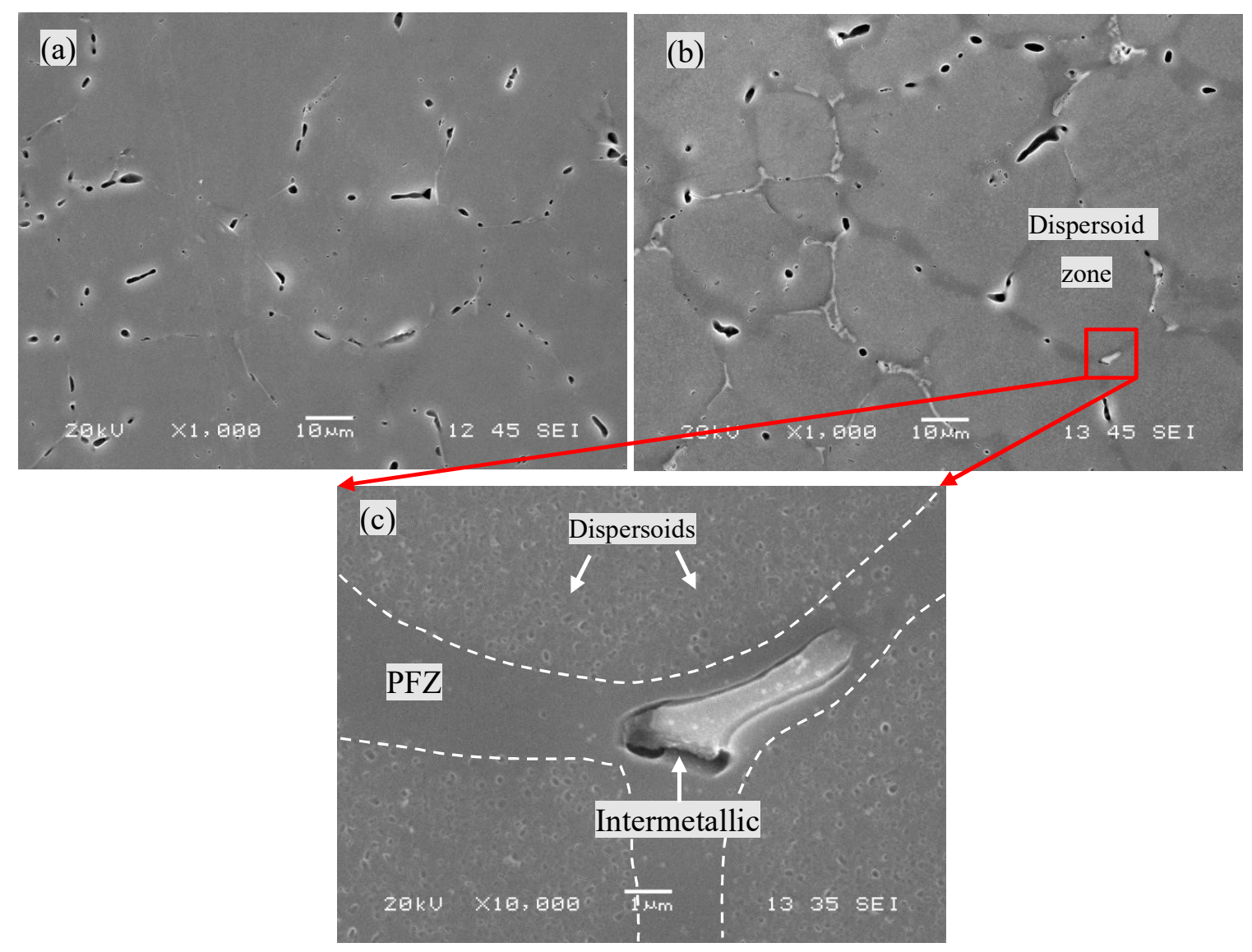

Fig. 2 Microstructures after the heat treatment and etching with $0.5 \%$ HF for $40 \mathrm{~s}$. (a) Base alloy without dispersoids, (b) $0.75 \mathrm{Mn}$ alloy with large dispersoid zones, and (c) enlarged image of that in Fig. $2 b$ showing the dispersoids and PFZ.

The dispersoids in the dispersoid zones in the three Mn-containing alloys were analyzed in detail using SEM at a high magnification (Fig. 3). Large numbers of fine dispersoids were uniformly distributed in the aluminum matrices of $0.5 \mathrm{Mn}, 0.75 \mathrm{Mn}$, and $1 \mathrm{Mn}$ (Fig. 3a-c, respectively). Fig. 3d shows a TEM image of typical dispersoids in the $0.75 \mathrm{Mn}$ alloy. The dispersoids appeared in various shapes, mostly short plates and rods, which can be attributed to the projection of the plate-like morphology into the two-dimensional image. The dispersoids were confirmed to be $\alpha-\mathrm{Al}(\mathrm{MnFe}) \mathrm{Si}$, according to the TEM-energy dispersive X-ray spectroscopy (EDXS) results (Fig. 3e) and previously reported data $[12,15,30]$. Fig. 4 shows the evolution of the number density and equivalent diameter of the dispersoid particles, obtained by the image analysis on a series of SEM images. The number density of the dispersoids increased with the Mn content from $9.7 \mu^{-2}$ in the $0.5 \mathrm{Mn}$ alloy to 11.5 and $17.2 \mu \mathrm{m}^{-2}$ in the $0.75 \mathrm{Mn}$ and $1 \mathrm{Mn}$ alloys, respectively. The mean equivalent diameters of the dispersoids in the three alloys were almost equal $(\sim 85 \mathrm{~nm})$. 

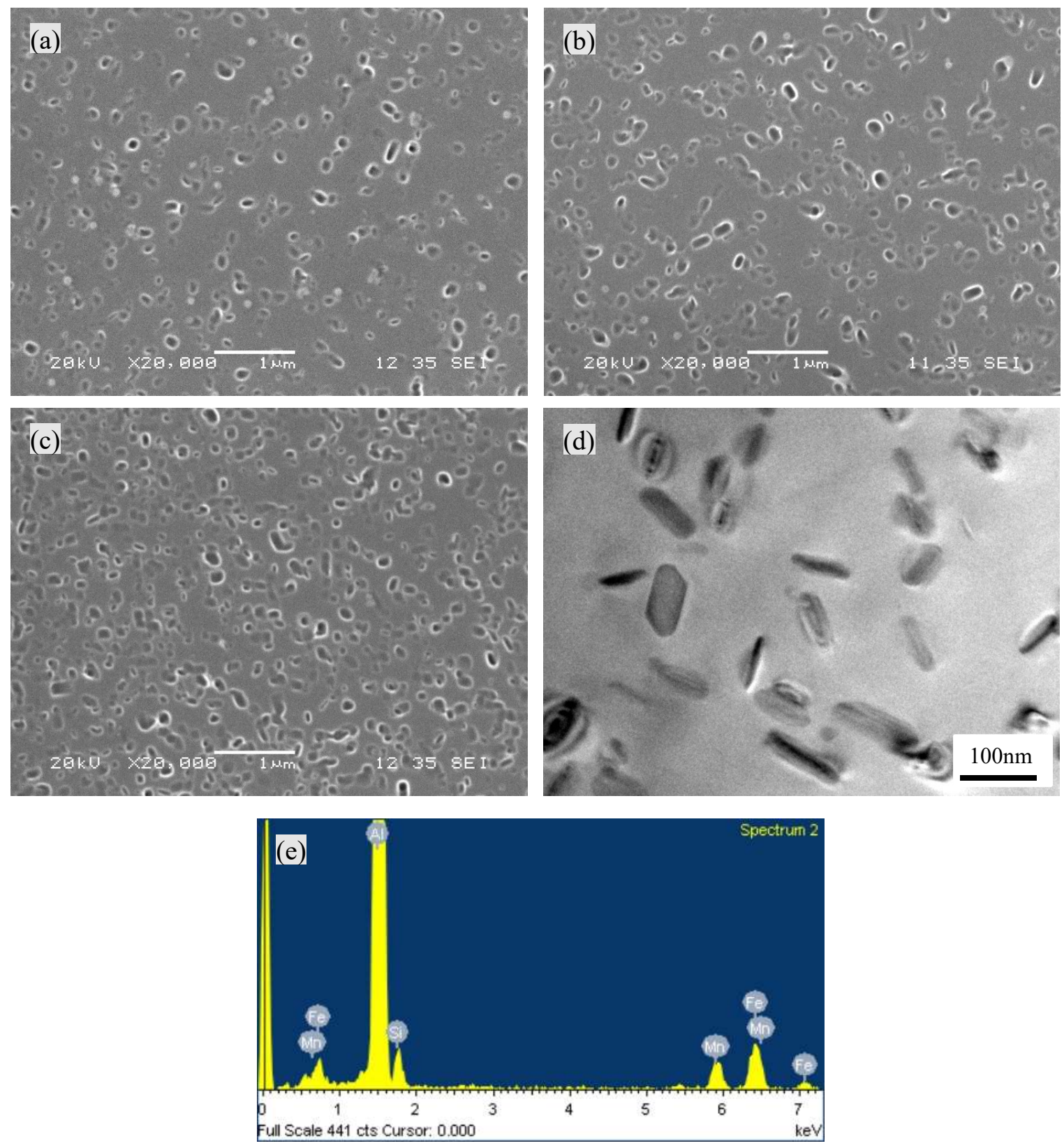

Fig. 3 SEM images of the etched samples of (a) $0.5 \mathrm{Mn}$, (b) $0.75 \mathrm{Mn}$, and (c) $1 \mathrm{Mn}$ alloys, (d) TEM image of $0.75 \mathrm{Mn}$ and (e) TEM-EDXS results for the dispersoids in $0.75 \mathrm{Mn}$ alloy. 


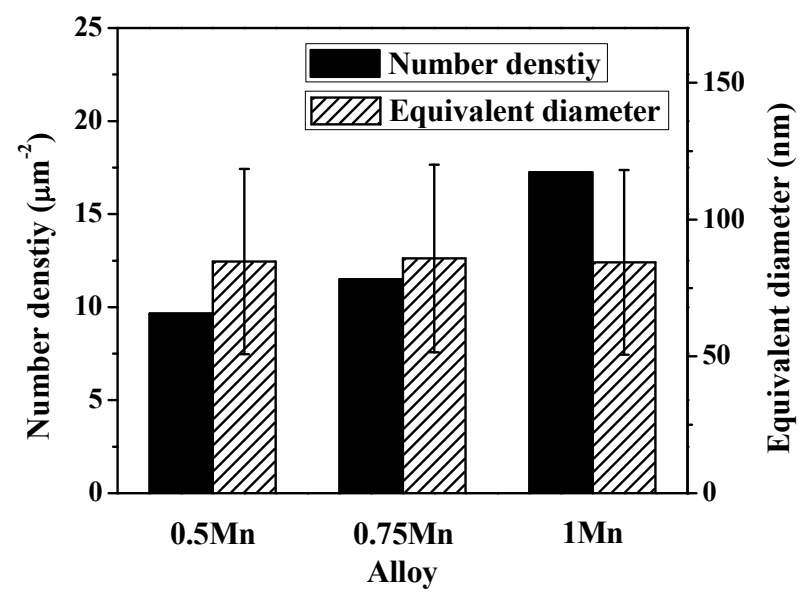

Fig. 4 Number density and equivalent diameter of dispersoids in the different alloys after heat treatment of $450{ }^{\circ} \mathrm{C}$ for $6 \mathrm{~h}$.

\subsection{High-temperature flow stress behavior}

High-temperature compression tests were performed at various deformation temperatures $\left(400\right.$ to $550{ }^{\circ} \mathrm{C}$ ) and strain rates $\left(1\right.$ to $\left.0.001 \mathrm{~s}^{-1}\right)$. Fig. 5 shows a series of typical true stress-true strain curves obtained under various hot deformation conditions for the four alloys. In general, the flow stress increased sharply at the beginning of the hot deformation reaching the peak value. Depending on the deformation conditions, the flow stress after the peak exhibited three types of trend, a) continuous but slow increase mostly under a high- $Z$ deformation condition (e.g., at $400{ }^{\circ} \mathrm{C}$ and $1 \mathrm{~s}^{-1}$ ), b) fairly stable (e.g., at $450{ }^{\circ} \mathrm{C}$ and $0.1 \mathrm{~s}^{-1}$ ), and c) continuous decrease until the end of the deformation at a relatively low $Z$ deformation condition, which is more evident starting from $500{ }^{\circ} \mathrm{C}$ and $0.01 \mathrm{~s}^{-1}$ toward the high deformation temperature and low strain rate in the three Mn-containing alloys (Fig. 5b-d). The different trends of the flow stress curves indicated the various balances of the work hardening and dynamic softening during the hot deformation [16,31].

As shown in Fig. 5, a general tendency was observed, i.e., the flow stress increased with the decrease in deformation temperature and increase in strain rate for all four alloys. On the other hand, the Mn addition led to a significant increase in flow stress.
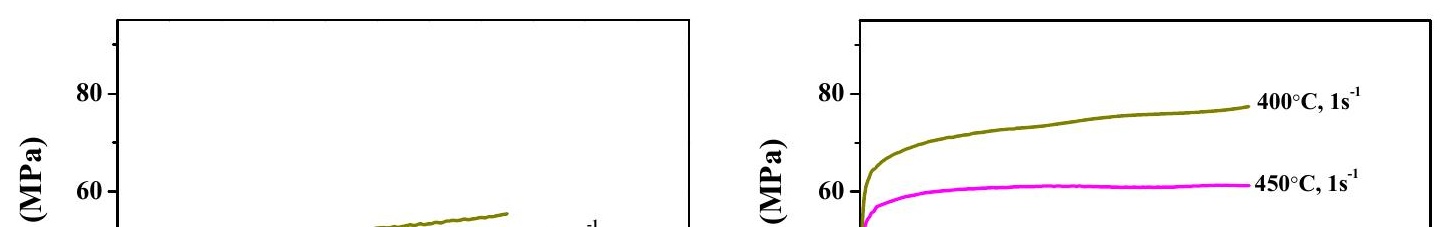

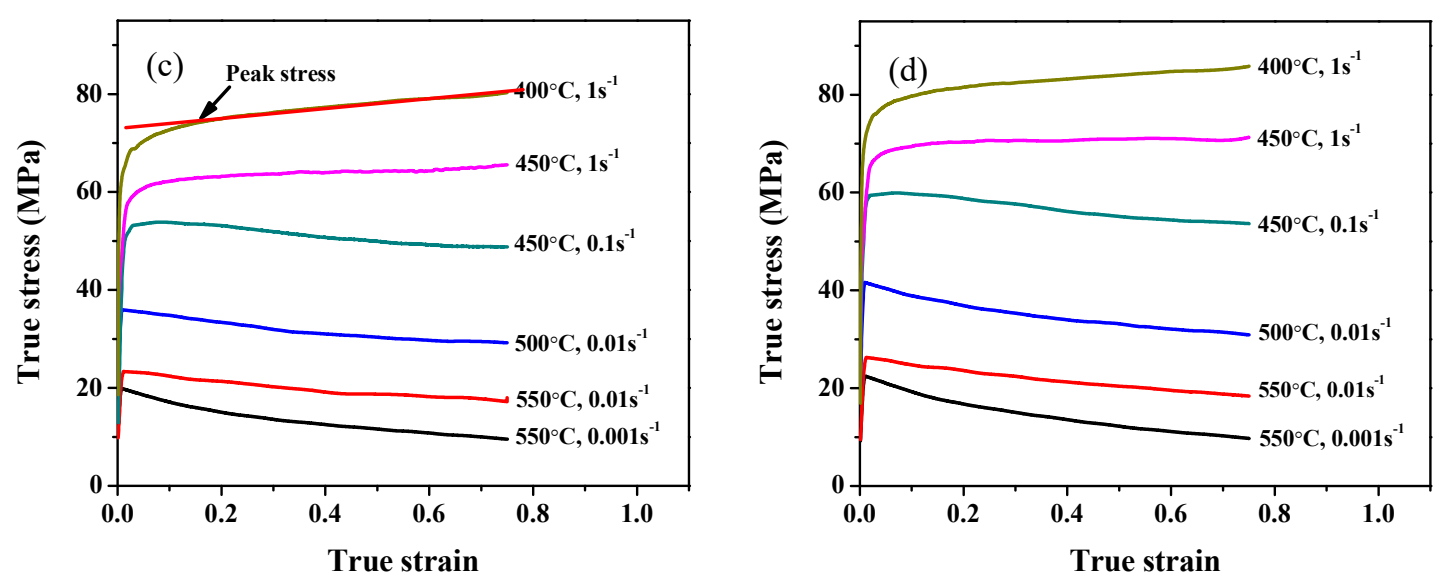

Fig. 5 Typical true stress-true strain curves during hot compression deformation, (a) base, (b) $0.5 \mathrm{Mn}$, (c) $0.75 \mathrm{Mn}$, and (d) $1 \mathrm{Mn}$ alloys.

For comparison of the flow stresses of the four alloys, the peak flow stresses were chosen to demonstrate the relationship between the Mn addition and flow stress. For the flow stress, which continuously increased during the hot deformation (e.g., at $400{ }^{\circ} \mathrm{C}$ and $1 \mathrm{~s}^{-1}$ ), the peak stress was identified as the tangent point on the flow curve by the extension of the line along the steady-state flow stress (outlined by the arrow and line in Fig. 5c) [24]. The peak flow stresses of the four alloys are plotted in Fig. 6 as functions of the deformation temperature and strain rate. Under given deformation condition, the flow stress significantly increased with the increase in Mn content to $0.5 \%$. With the further increase in Mn content to 0.75 and $1 \%$, the flow stress exhibited a moderate increase. For example, under identical deformation conditions $\left(400{ }^{\circ} \mathrm{C}\right.$ and $0.01 \mathrm{~s}^{-1}$, Fig. 6a), the flow stress increased from $26 \mathrm{MPa}$ for the base alloy to $51 \mathrm{MPa}$ for the $0.5 \mathrm{Mn}$ alloy, an increase almost by a factor of two. With the further increase in $\mathrm{Mn}$ content, the flow stress moderately increased to $55 \mathrm{MPa}$ for $0.75 \mathrm{Mn}$ and $63 \mathrm{MPa}$ for $1 \mathrm{Mn}$. Compared to that of the base alloy, the flow stresses of the three Mncontaining alloys are considerably higher, indicating the enhanced deformation 
resistance after the dispersoid formation. The increased flow stress with the increase in Mn content is consistent with the increased number density of the dispersoids in the alloy (Fig. 4).
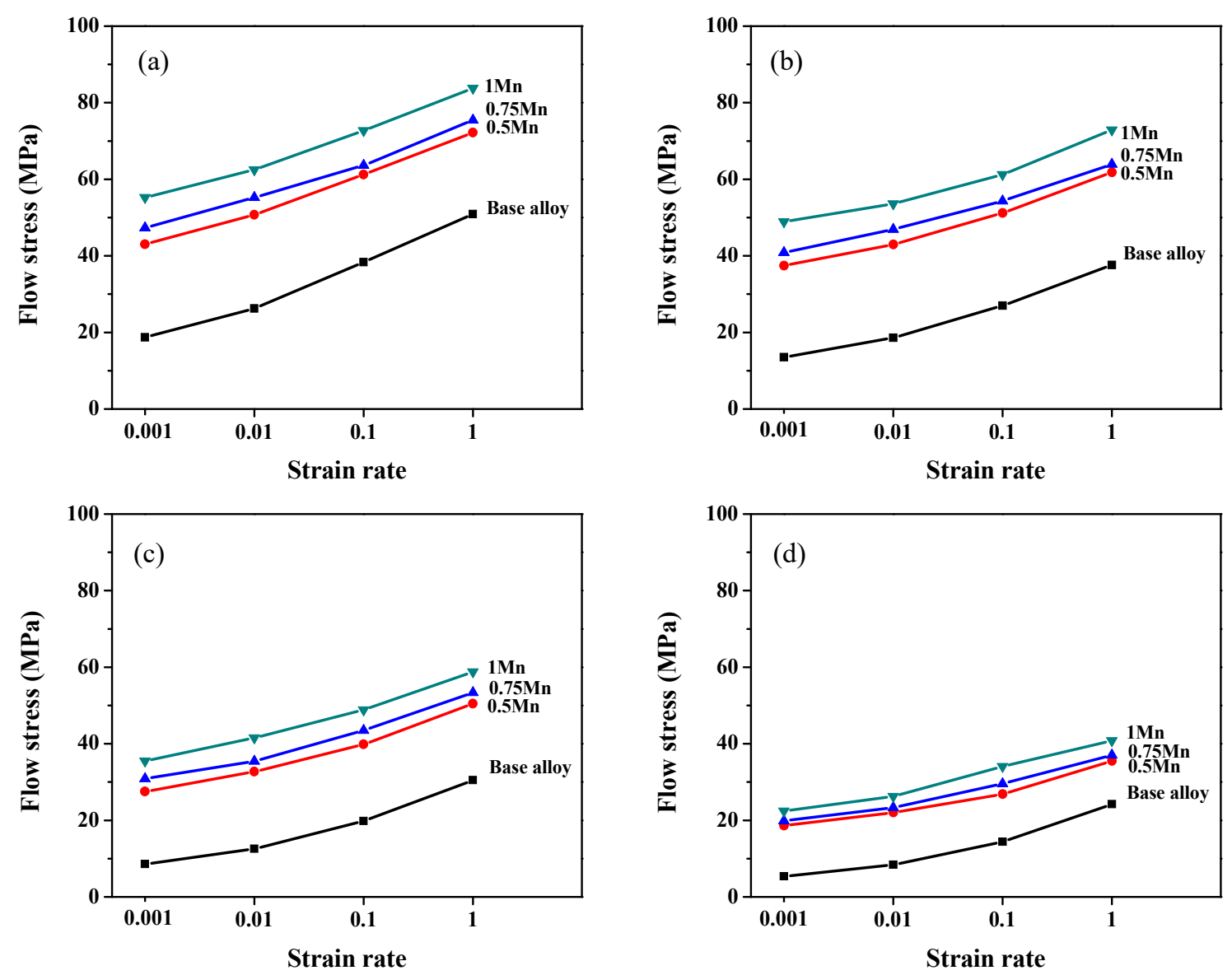

Fig. 6 Typical flow stresses of four experimental alloys at the hot deformation temperature of (a) $400{ }^{\circ} \mathrm{C}$, (b) $450{ }^{\circ} \mathrm{C}$, (c) $500{ }^{\circ} \mathrm{C}$, and (d) $550{ }^{\circ} \mathrm{C}$ as a function of the strain rate.

\subsection{Constitutive analyses}

The hyperbolic-sine equation, proposed by Sellars and Mc Tegart [21], is widely used to demonstrate the relationship between the strain rate, deformation temperature, and flow stress, particularly over a wide range of stresses:

$$
Z=\dot{\varepsilon} \exp \left(\frac{\mathrm{Q}}{\mathrm{RT}}\right)=A[\sinh (\alpha \sigma)]^{n}
$$

where $Z$ is the Zener-Hollomon parameter, $\dot{\varepsilon}$ is the deformation strain rate, $n$ and $A$ are material constants, $\alpha$ is the stress multiplier, $\sigma$ is the flow stress (MPa), $Q$ is the activation energy for hot deformation $(\mathrm{kJ} / \mathrm{mol}), R$ is the universal gas constant $(8.314$ $\mathrm{J} / \mathrm{mol} \mathrm{K}$ ), and $T$ is the deformation temperature $(\mathrm{K})$. The experimental flow stress data 
for the $0.75 \mathrm{Mn}$ alloy were used as an example to derive the activation energy $Q$ and material constants. The flow stress, $\sigma$, was obtained using the peak stress. The stress multiplier, $\alpha$, was defined as $\alpha=\beta / n_{1}$, where $\beta$ and $n_{1}$ were evaluated using the mean slopes of the plots of $\ln \dot{\varepsilon}-\sigma$ and $\ln \dot{\varepsilon}-\ln \sigma$, respectively, for the range of experimental deformation temperatures. The mean values of $\beta$ and $n_{1}$ were determined using the results in Fig. 7, while $\alpha$ of $0.75 \mathrm{Mn}$ was calculated to be $0.023 \mathrm{MPa}^{-1}$.
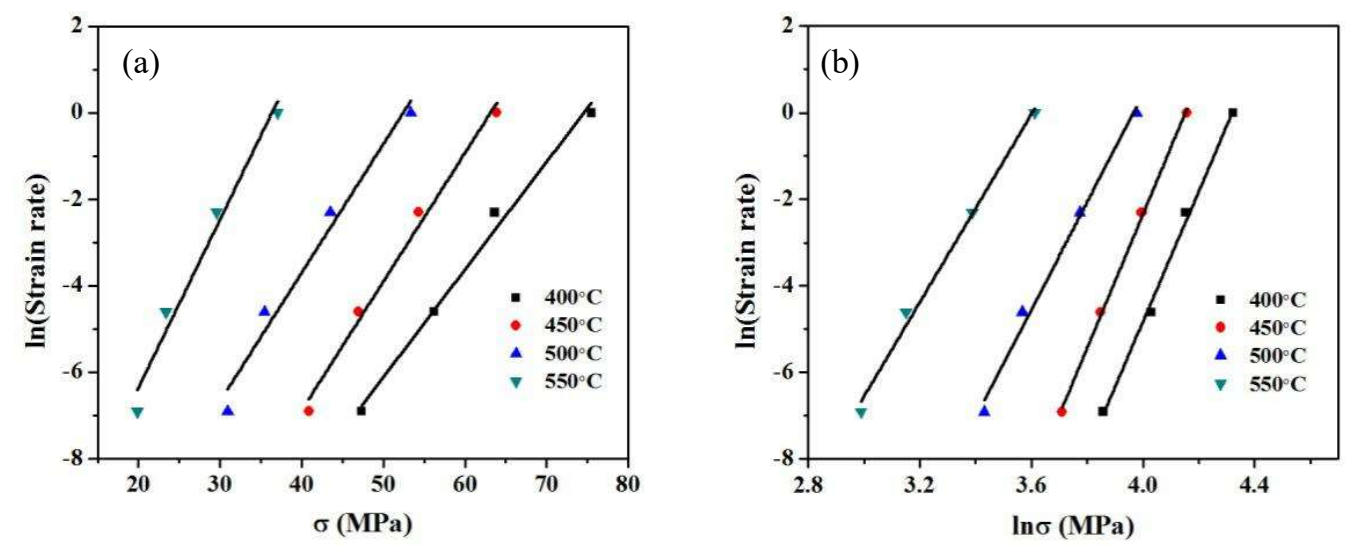

Fig. 7 Relationships between (a) $\ln \dot{\varepsilon}$ and $\sigma$ and (b) $\ln \dot{\varepsilon}$ and $\ln \sigma$.

Differentiating Eq. (1) yields the following:

$$
\mathrm{Q}=\mathrm{R}\left[\frac{\partial \ln \dot{\varepsilon}}{\partial \ln \left[\sinh \alpha \sigma_{p}\right]}\right]_{T}\left[\frac{\partial \ln [\sinh \alpha \sigma]}{\partial(1 / T)}\right]_{\dot{\varepsilon}}=\mathrm{RnS}
$$

where $n$ is the mean slope of the plots of $\ln \dot{\varepsilon}-\ln [\sinh (\alpha \sigma)]$ at various temperatures and $S$ is the mean slope of the plots of $\ln [\sinh (\alpha \sigma)]-1 / T$ at different strain rates. The relationship between $\ln \dot{\varepsilon}$ and $\ln [\sinh (\alpha \sigma)]$, derived using the measured flow stresses (Fig. 6), was calculated (Fig. 8a). The mean value of the slopes at the four different deformation temperatures, $n$, was then calculated to be 9.85. In addition, the relationship of $\ln [\sinh (\alpha \sigma)]-1 / T$ is plotted in Fig. 8b. The mean slope $S$ at various strain rates was 3.77. The activation energy $Q$ could be then calculated by Eq. (2), yielding a value of $308.7 \mathrm{~kJ} / \mathrm{mol}$ for $0.75 \mathrm{Mn}$ alloy.

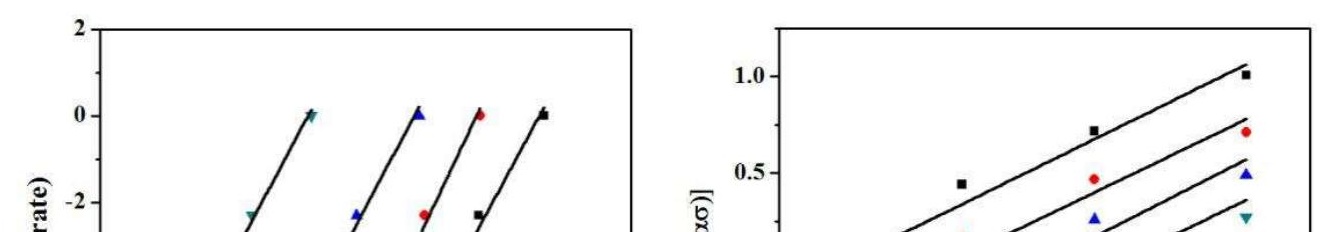


Fig. 8 Relationships between (a) $\ln \dot{\varepsilon}$ and $\ln [\sinh (\alpha \sigma)]$ and (b) $\ln [\sinh (\alpha \sigma)]$ and 1000/T.

The application of natural logarithm on both sides of Eq. (1) yields,

$$
\ln Z=\ln A+n \ln [\sinh (\alpha \sigma)]
$$

where $\ln (\mathrm{A})$ is obtained as the intercept of the plot of $\ln Z-\ln [\sinh (\alpha \sigma)]$, as shown in Fig. 9.

In a similar manner, the material constants $A, n$, and $\alpha$ and activation energies $Q$ were calculated according to Eqs. 1-3 for all studied alloys, as shown in Table 2. With the increase in Mn content, $\alpha$ decreased whereas $n, A$, and $Q$ increased. Compared to that of the base alloy $(191.2 \mathrm{~kJ} / \mathrm{mol})$, the $0.5 \mathrm{Mn}$ alloy exhibited a significantly increased $Q(285.6 \mathrm{~kJ} / \mathrm{mol})$ value. With the further increase in $\mathrm{Mn}$ content, the $0.75 \mathrm{Mn}$ and $1 \mathrm{Mn}$ alloys exhibited moderately increased $Q$ values of 301.2 and $315.4 \mathrm{~kJ} / \mathrm{mol}$, respectively.

Among the material constants, the activation energy for hot deformation $Q$ is an important indicator of the difficulty degree of plastic deformation. $Q$ of the base alloy $(191 \mathrm{~kJ} / \mathrm{mol})$ is generally in agreement with the value reported for a similar alloy (185 $\mathrm{kJ} / \mathrm{mol}$ ) [32]. However, it is considerably higher than those of pure aluminum (145 $\mathrm{kJ} / \mathrm{mol}$ ) [16] and dilute Al-Fe-Si alloy (161 kJ/mol) [21], owing to the pinning effect of the high amount of intermetallics and high solute alloying element contents in the aluminum matrix on dislocation glides. $Q$ of a 6082 alloy having a similar chemistry to that of the base alloy but under the full-solution-treated condition was $269 \mathrm{~kJ} / \mathrm{mol}$ [33]. The large difference is most likely attributed to the high solid solution levels of alloying elements (particularly $\mathrm{Mg}$ and $\mathrm{Si}$ ) in the aluminum matrix provided by the full solution treatment, while most $\mathrm{Mg}$ and $\mathrm{Si}$ were still bonded in the primary $\mathrm{Mg}_{2} \mathrm{Si}$ in the base alloy in this study because of the low homogenization temperature of $450{ }^{\circ} \mathrm{C}$. The three Mn-containing alloys $(0.5 \mathrm{Mn}, 0.75 \mathrm{Mn}$, and $1 \mathrm{Mn})$ exhibited significant increases in activation energy, indicating a very strong effect of the large number of dispersoids on the dislocation movement and hence on the deformation resistance during the hot working. Distinct increases in $Q$ and corresponding resistance of hot deformation owing 
to the $\mathrm{Zr}$ - and $\mathrm{V}$-containing dispersoids in 7150 aluminum alloys were also reported in $[19,20]$.

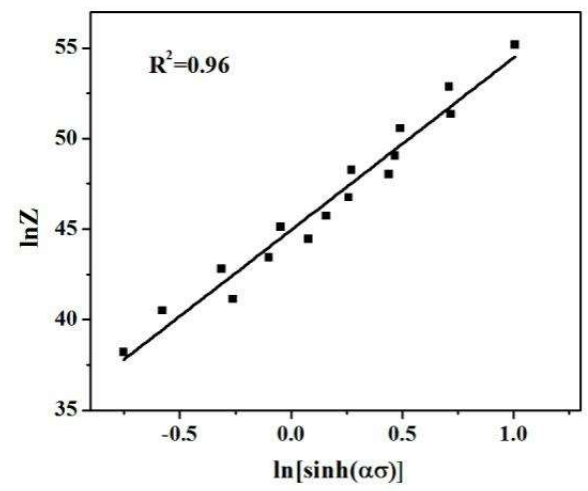

Fig. 9 Relationship between $\ln Z$ and $\ln [\sinh (\alpha \sigma)]$.

Table 2 Values of material constants and activation energies of four alloys studied.

\begin{tabular}{lllll}
\hline Alloys & $\alpha\left(\mathrm{MPa}^{-1}\right)$ & $\mathrm{n}$ & $\mathrm{A}\left(\mathrm{s}^{-1}\right)$ & $\mathrm{Q}(\mathrm{kJ} / \mathrm{mol})$ \\
\hline Base & 0.054 & 4.27 & $2.54 \mathrm{E}+11$ & 191.2 \\
$0.5 \mathrm{Mn}$ & 0.025 & 8.98 & $8.72 \mathrm{E}+17$ & 285.6 \\
$0.75 \mathrm{Mn}$ & 0.023 & 10.04 & $9.34 \mathrm{E}+18$ & 301.2 \\
$1 \mathrm{Mn}$ & 0.021 & 10.40 & $7.29 \mathrm{E}+19$ & 315.4 \\
\hline
\end{tabular}

\subsection{Microstructural evolution during hot deformation}

The EBSD technique was used to investigate the grain and subgrain structures after the hot deformation. Three typical deformation conditions, $400{ }^{\circ} \mathrm{C} / 0.1 \mathrm{~s}^{-1}$, $500{ }^{\circ} \mathrm{C} / 0.01 \mathrm{~s}^{-1}$, and $550{ }^{\circ} \mathrm{C} / 0.001 \mathrm{~s}^{-1}$, were selected representing the high-, medium-, and low- $Z$ conditions, respectively. Fig. $11-10$ shows all Euler orientation maps of the deformed samples of the four alloys under the three deformation conditions, in which different colors represent the orientation differences of grains and subgrains. In addition, the misorientation angle distributions of the boundaries for the four alloys were quantified to provide a more detailed information on the microstructural evolution under the same $Z$ deformation conditions; the results are presented in Fig. 12.

Mainly elongated grains perpendicular to the compression direction were observed in all deformed samples (Fig. 1011). At the high $Z\left(400{ }^{\circ} \mathrm{C}, 0.1 \mathrm{~s}^{-1}\right)$, large numbers of low- and medium-angle boundaries in the deformed microstructures were observed (Fig. 1 ㄴa, $\mathrm{d}, \mathrm{g}$, and $\mathrm{j}$ ), indicating the high densities of dislocation cells and subgrains. These microstructures were typically characterized by DRV. It should be noted that in the Gleeble compression tests when the samples were deformed to a true strain of 0.75 , they were subjected to an immediate water quenching. Therefore, all deformed microstructures in Fig. $1 \underline{0} 1$ exhibited DRV or DRX. The level of DRV varied with the 
Mn content, which can be demonstrated by the misorientation angle distributions in Fig. $11 z \mathrm{a}$. Compared to those of the base alloy, the three Mn-containing alloys $(0.5 \mathrm{Mn}$, $0.75 \mathrm{Mn}$, and $0.75 \mathrm{Mn})$, overall, have higher fractions of low-angle boundaries $\left(2-5^{\circ}\right)$ and lower fractions of high-angle boundaries $\left(>15^{\circ}\right)$, suggesting the larger restriction effect on the DRV owing to the large number of dispersions. The $1 \mathrm{Mn}$ alloy has the lowest fraction of high-angle boundaries, yielding the largest restriction effect on the DRV.

For the deformation at the medium $Z\left(500{ }^{\circ} \mathrm{C}, 0.01 \mathrm{~s}^{-1}\right)$, the substructures were better organized with lower substructure densities (Fig. 1ㅁtb, e, h, and k). Correspondingly, the fraction of low-angle boundaries $\left(1-5^{\circ}\right)$ was reduced, while that of high-angle boundaries was increased (Fig. 11 zb), which implies an increase in DRV level as $Z$ was reduced. In the deformed microstructure of the base alloy, an uneven distribution of low-angle boundaries (white line) was observed in the different grains, as indicated in Fig. 10tb. For example, in grain 1, the high density of low-angle boundaries was still observed, while in grain 2, the low-angle boundaries were almost removed, leaving only few well-ranged low- and medium-angle boundaries. This result indicates that, in some grains, low-angle boundaries were progressively combined or converted into medium-angle boundaries, which in turn led to new grains, without lowangle or even medium-angle boundaries. This evolution can be considered as the occurrence of DRX [28,34], which also corresponds to the remarkable increase in fraction of high-angle boundaries compared to that in the sample deformed at the high $Z$ (Fig. 12a and b). However, in $0.5 \mathrm{Mn}, 0.75 \mathrm{Mn}$, and $1 \mathrm{Mn}$ alloys, no such phenomenon was observed and thus the DRV was still the predominant mechanism (Fig. 11e 10e, h, and $\mathrm{k}$ ), which is consistent with the relatively low content of high-angle boundaries, shown in Fig. 12b11b.

Under the low- $Z$ deformation condition $\left(550{ }^{\circ} \mathrm{C}, 0.001 \mathrm{~s}^{-1}\right)$, large reductions in substructure density were observed for all alloys (Fig. 11e10c, f, i, and 1), characterized with the overall lower fractions of low-angle boundaries and higher fractions of highangle boundaries (Fig. $12 \mathrm{e} 11 \mathrm{c}$ ). In the base alloy (Fig. 11e $\underline{10 \mathrm{c}}$ ), the low- and mediumangle boundaries almost disappeared and the grains almost did not exhibit internal substructures. In general, the disappearance of low- and medium-angle boundaries could be attributed to both DRV and DRX [16]. However, in this case, a series of highangle boundaries parallel to the compression direction appeared (see arrows in Fig. $11 \mathrm{e} 10 \mathrm{c})$, the original deformed and elongated grains had been broken up and replaced by newly recrystallized grains via the migration of high-angle boundaries. In addition, the results of the boundary angle distribution (Fig. $12 \mathrm{e} 11 \mathrm{c}$ ) revealed that the fraction of the low- and medium-angle boundaries was as low as $20 \%$, while that of the high-angle boundaries was larger than $70 \%$. Therefore, the grain structure of the base alloy is almost full DRX. In the $0.5 \mathrm{Mn}, 0.75 \mathrm{Mn}$ and $1 \mathrm{Mn}$ alloys, considerable numbers of low- 
and medium-angle boundaries were still observed in the deformed grains (Fig. 11f $\underline{10 f}$, $\mathrm{i}$, and 1). However, newly formed grains could be observed near the original grain boundaries. These new grains were small and equiaxed without internal substructures and their sizes were in the range of 5 to $20 \mu \mathrm{m}$, indicating a partial DRX during the hot deformation. Compared to those of the base alloy, the fraction of the high-angle boundaries significantly decreased, while the fractions of the low- and medium-angle boundaries increased (Fig. $12 \mathrm{el1c}$ ). Therefore, the large numbers of dispersoids in the three Mn-containing alloys could effectively inhibit the DRX.

The small recrystallized grains were located mostly near the original grain boundaries in the Mn-containing alloys, which were considered to be closely related to the PFZs (Fig. 2b and c). During the hot deformation, the DRX occurred preferentially in the regions where the dislocation movement and subgrain boundary migration easily occurred [16]. Therefore, the PFZs without dispersoids were the preferred locations of DRX. However, once the dislocation movement and subgrain boundary migration encountered the dispersoid zone, the ongoing DRX was limited. Therefore, the recrystallized grains were restricted in the PFZs and the growth of such grains was limited.

Based on the EBSD data, a quantitative analysis of the mean misorientation angle of the boundaries and subgrain size was performed for the four alloys. Fig. 13-12 shows the mean misorientation angles of the boundaries in the alloys under the three $Z$ deformation conditions. With the shift in deformation from the high to the low $Z$, with the increased temperature and decreased strain rate, the mean misorientation angles of the boundaries of the four alloys were generally increased, suggesting the increased DRV/DRX levels with the decrease in $Z$. For the base alloy, the mean misorientation angle of the boundaries significantly increased. This is consistent with the transition of the deformed microstructure from the recovered microstructure at the high $Z$ through the partially recrystallized microstructure to the fully recrystallized microstructure at the low $Z$. For the three Mn-containing alloys, the mean misorientation angles of the boundaries were relatively low (below $15^{\circ}$ ) at both high and medium $Z$ values. Toward low $Z$ values, they increased slightly to values above $15^{\circ}$, indicating a partially recrystallized microstructure. At any given $Z$, there is a sharp drop in the mean misorientation angles from the base alloy to the $0.5 \mathrm{Mn}$ alloy, while the differences in mean misorientation angle between the three Mn-containing alloys were small.

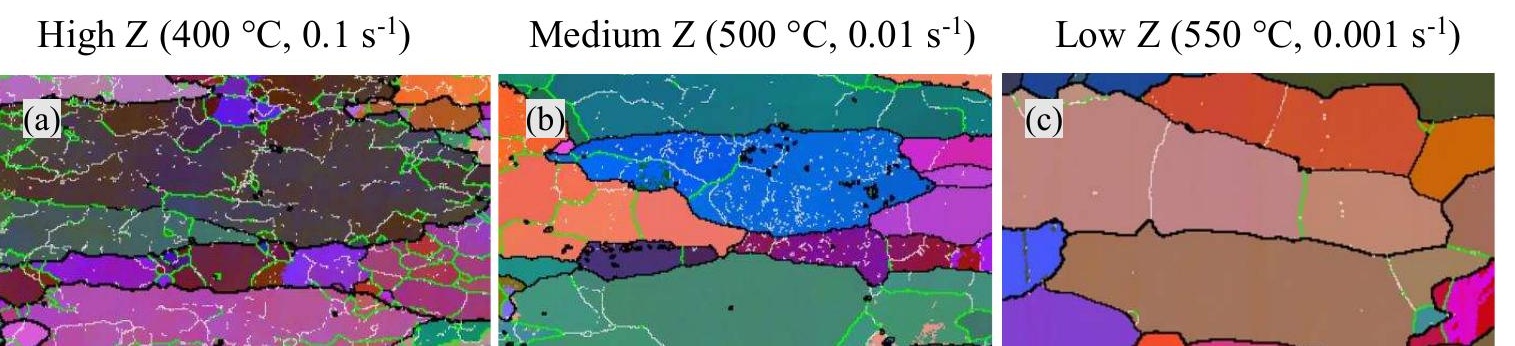


Base alloy

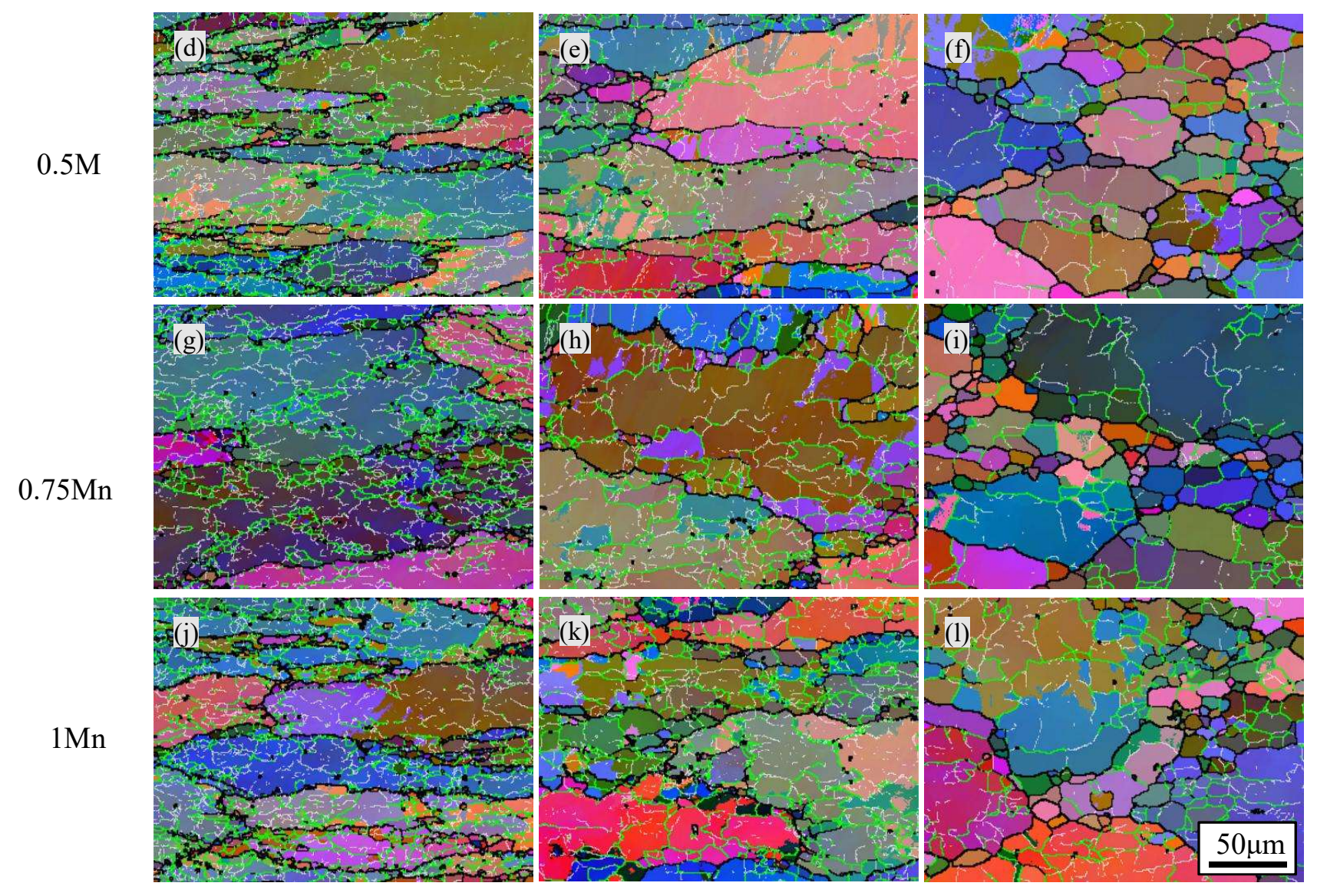

Fig. 11-10 All Euler orientation maps of four alloys under various deformation conditions. The boundary misorientation angles are marked by white lines $2-5^{\circ}$, green lines $5-15^{\circ}$ and black lines $>15^{\circ}$.
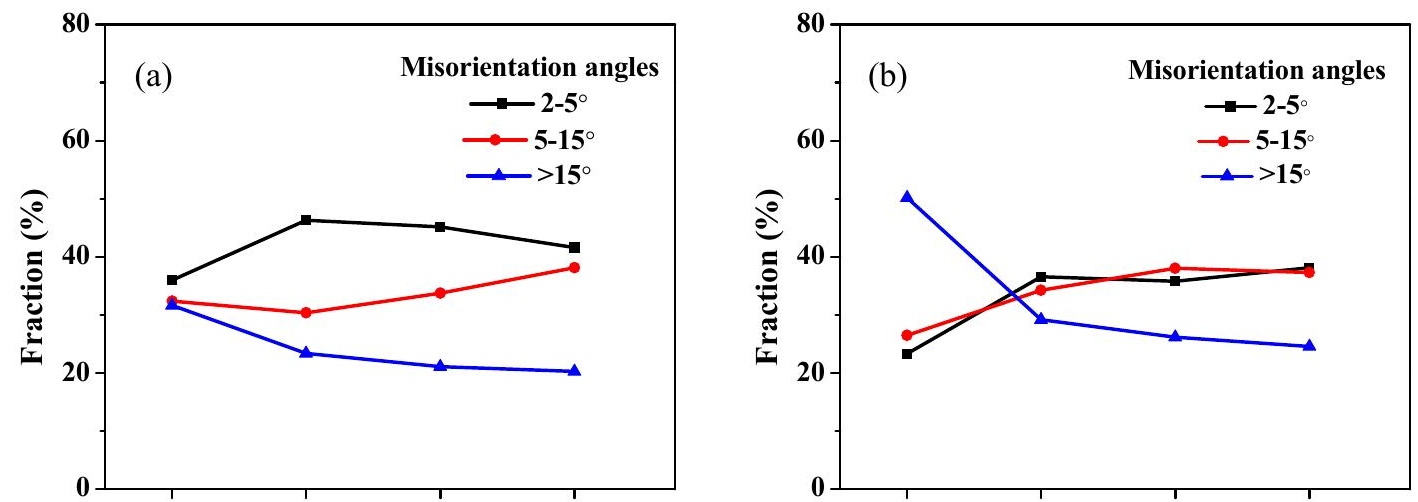


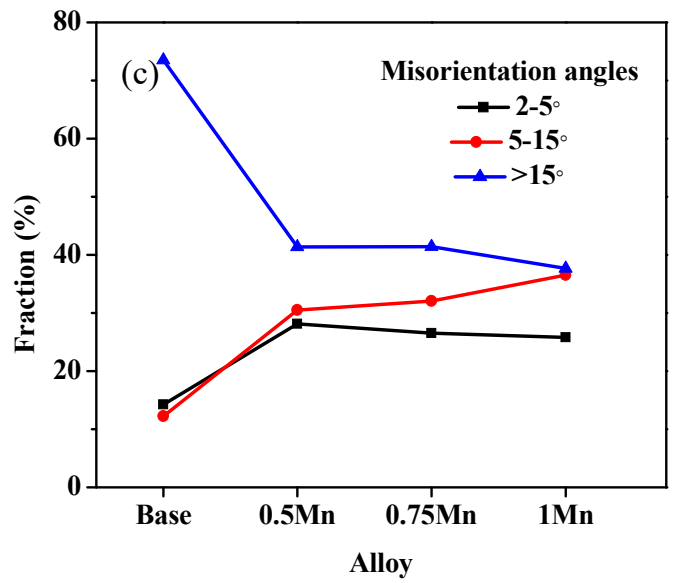

Fig. 12 11 Evolution of misorientation angle distribution of boundaries as a function of Mn content under different deformation conditions: (a) High $Z\left(400{ }^{\circ} \mathrm{C}, 0.1 \mathrm{~s}^{-1}\right)$; (b) Medium Z $\left(500{ }^{\circ} \mathrm{C}, 0.01 \mathrm{~s}^{-1}\right)$, and (c) Low Z $\left(550^{\circ} \mathrm{C}, 0.001 \mathrm{~s}^{-1}\right)$

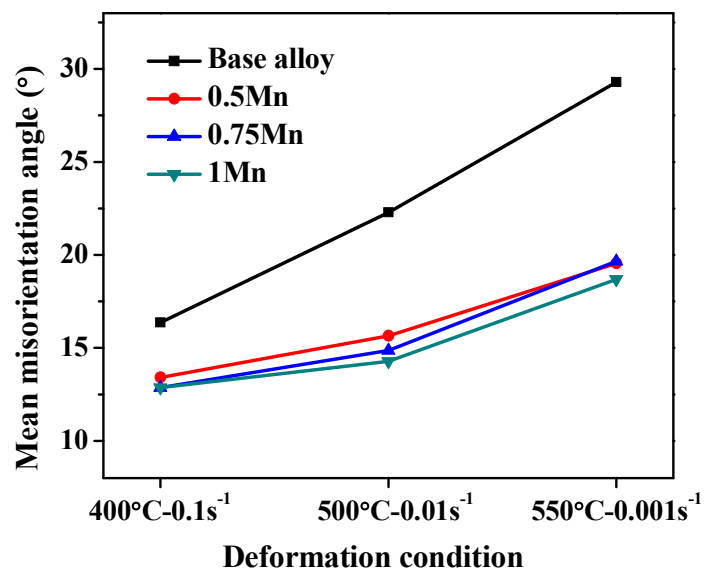

Fig. 13-12 Mean misorientation angles of boundaries in four experimental alloys under different deformation conditions.

Fig. 14a 13 a shows the influences of the deformation conditions on the subgrain sizes of the alloys. The general tendency of the subgrain size change is very similar with the mean misorientation angle change. It increased with the decrease in $Z$ and decreased with the increase in Mn content. At the high $Z$, the subgrain sizes of the four 
alloys were quite low (in the range of 2.8-7.6 $\mu \mathrm{m}$ ), indicating strong restrictions on the DRVs during the deformation [35]. At the medium and low $Z$ values, the subgrain sizes of the base alloy significantly increased, reaching values as large as 17 and $39 \mu \mathrm{m}$, respectively, while the subgrain sizes of the $0.5 \mathrm{Mn}, 0.75 \mathrm{Mn}$ and $1 \mathrm{Mn}$ alloys increased only moderately (mostly below $10 \mu \mathrm{m}$ ). This also reveals the strong effects of the $\mathrm{Mn}$ addition and dispersoids on the retardation of the DRV/DRX during the hot deformation. Fig. $14 \mathrm{~b}-13 \mathrm{~b}$ shows the relationship between the flow stress $\sigma$ and subgrain size $d$. The flow stress increased with the decrease in subgrain size. A good linear relationship between the flow stress and subgrain size can be established based on Eq. 4, proposed by McQueen et al. [36] and Jonas et al. [37].

$$
\sigma=212.99 d^{-1}-3.26
$$

This relationship is in good agreement with the results reported for aluminum alloys under hot compression, torsion, and extrusion [37-39]. It shows that both deformation conditions and Mn content influence the subgrain size (Fig. 14a13a), which in turn determines the flow stress (Fig. 14b13b) [16].
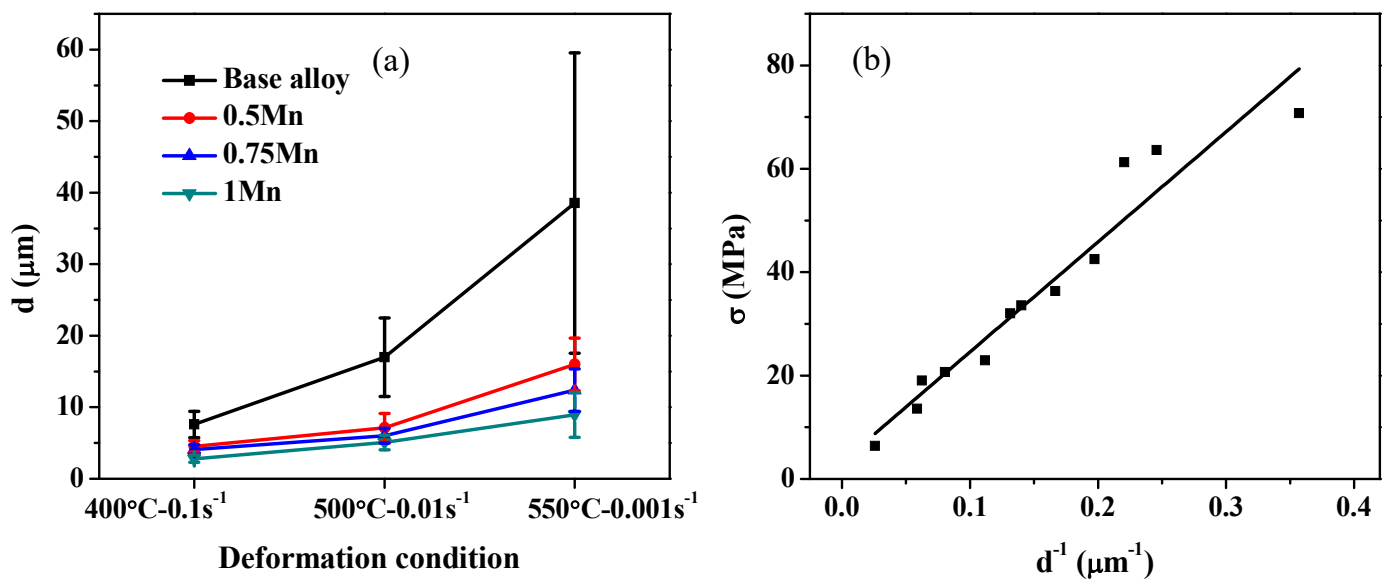

Fig. 14 13 (a) Subgrain size under different deformation conditions and (b) Relationship between flow stress and reciprocal subgrain size in the experimental alloys. 


\section{Discussion}

The hot deformation behaviors of 6082 aluminum alloys with different Mn contents were systematically studied. With the addition of $\mathrm{Mn}(0.5$ to $1 \%)$, a large number of $\alpha$ $\mathrm{Al}(\mathrm{MnFe}) \mathrm{Si}$ dispersoids were formed by the low-temperature homogenization treatment at $450{ }^{\circ} \mathrm{C}$ for $6 \mathrm{~h}$. The number density of the dispersoids increased with the Mn content, whereas the dispersoid size was almost unchanged. The dispersoids increased the high-temperature flow stress and hence the activation energy. They also promoted the retardation of DRV and inhibition of DRX in the deformed microstructure.

\subsection{Effect of the dispersoids on the DRV/DRX}

In general, the levels of DRV and DRX decreased after the alloying with Mn (Fig. 11 1310-12). When Mn was added, the precipitation of the large number of dispersoids had an important role in the dynamic softening. Fig. 15a-14a shows the interaction of the $\alpha-\mathrm{Al}(\mathrm{MnFe}) \mathrm{Si}$ dispersoids with dislocations in the $0.75 \mathrm{Mn}$ alloy under the deformation conditions of $450{ }^{\circ} \mathrm{C} / 0.01 \mathrm{~s}^{-1}$. The dislocations were retarded at the points where they encountered the dispersoids, and thus the dispersoids acted as stronger barriers to deformation. Fig. $15 \mathrm{~b}-14 \mathrm{~b}$ shows the interaction of the dispersoids with subgrain boundaries of the same alloy under the same deformation conditions. The subgrain boundaries, formed through piled-up dislocations during the deformation, were strongly pinned by the dispersoids, restricting the subgrain migration and rotation $[16,35,40]$. In this manner, the DRV and DRX were restrained owing to the high number of dispersoids $[3,41]$. On the other hand, the strong pinning effect of the dispersoids on dislocation slips and subgrain rotations yielded significant increases in flow stress and activation energy $Q$ compared to the case of the base alloy without dispersoids.
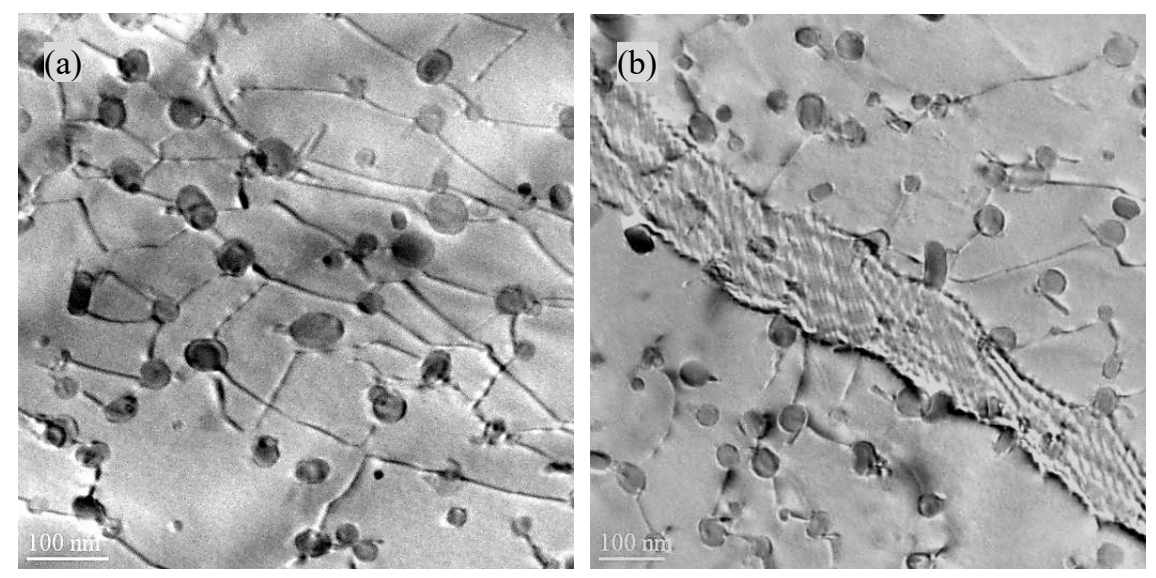

Fig. 15-14 Interactions of dispersoids with dislocations (a) and with subgrain boundaries (b) in $0.75 \mathrm{Mn}$ alloy at the deformation condition of $450{ }^{\circ} \mathrm{C}$ and $0.01 \mathrm{~s}^{-1}$. 
In addition to those under the three typical deformation conditions presented above, the microstructure changes after hot deformation under other deformation conditions were also analyzed by the EBSD technique. Table 3 shows a comparison of the DRV/DRX in the base and Mn-containing alloys. Although the DRV and DRX levels of the three Mn-containing alloys were slightly different, the occurrence conditions of DRX in $0.5 \mathrm{Mn}, 0.75 \mathrm{Mn}$, and $1 \mathrm{Mn}$ alloys were almost identical and thus were regrouped into one group (Table 3b). In the base alloy (Table 3a), DRV was the main softening mechanism at the deformation temperatures lower than $450{ }^{\circ} \mathrm{C}$ and strain rates higher than $0.01 \mathrm{~s}^{-1}$. The DRX occurred at $500^{\circ} \mathrm{C}$ and strain rates of 0.01 and $0.001 \mathrm{~s}^{-1}$, yielding a partial DRX microstructure. With the increase in deformation temperature to $550{ }^{\circ} \mathrm{C}$, full DRX occurred. For the Mn-containing alloys, it seems that when a sufficient number of dispersoids existed in the matrix (starting from $0.5 \mathrm{Mn}$ alloy), the further increase in number density of dispersoids $(0.75 \mathrm{Mn}$ and $1 \mathrm{Mn})$ had smaller effects on the DRV and DRX. The DRX in these three alloys started at $500{ }^{\circ} \mathrm{C} / 0.001 \mathrm{~s}^{-1}$ with a small number of recrystallized grains. At $550{ }^{\circ} \mathrm{C}$ and 0.01 and $0.001 \mathrm{~s}^{-1}$, a partial DRX microstructure was formed with a moderate number of recrystallized grains. The results indicated the onsets of DRX of the Mn-containing alloys requiring higher deformation temperatures and lower strain rates than those of the base alloy, which is attributed to the strong inhibition effect of the dispersoids on the DRX.

Table 3 DRV/DRX in (a) the base alloy and (b) the Mn-containing alloys at various deformation conditions

(a)

\begin{tabular}{|c|c|c|c|c|}
\hline$\dot{\varepsilon}\left(\mathrm{s}^{-1}\right)$ & 1 & 0.1 & 0.01 & 0.001 \\
\hline $400{ }^{\circ} \mathrm{C}$ & DRV & DRV & DRV & \\
\hline $450{ }^{\circ} \mathrm{C}$ & DRV & DRV & DRV & \\
\hline $500{ }^{\circ} \mathrm{C}$ & & DRV & DRV & DRV \\
\hline $550{ }^{\circ} \mathrm{C}$ & & & DRX & DRX \\
\hline
\end{tabular}

(b)

\begin{tabular}{|c|c|c|c|c|}
\hline$\dot{\varepsilon}\left(\mathrm{s}^{-1}\right)$ & 1 & 0.1 & 0.01 & 0.001 \\
\hline $400{ }^{\circ} \mathrm{C}$ & DRV & DRV & DRV & \\
\hline $450{ }^{\circ} \mathrm{C}$ & DRV & DRV & DRV & \\
\hline $500{ }^{\circ} \mathrm{C}$ & & DRV & DRV & DRV \\
\hline $550{ }^{\circ} \mathrm{C}$ & & & DRV & DRV \\
\hline
\end{tabular}

\subsection{Variation in activation energy with the deformation strain}

The calculation of the activation energy $Q$ and material constants presented above (Table 2) was based on the peak flow stresses obtained in the true stress-strain curves (Fig. 5). However, in the three Mn-containing alloys (0.5Mn, $0.75 \mathrm{Mn}$, and $1 \mathrm{Mn}$ ), the 
flow stresses largely decreased with the increase in strain at a relatively low $Z$ after reaching the peak flow stress at the early stage of the deformation. This could be observed at $500{ }^{\circ} \mathrm{C}$ and $0.01-0.001 \mathrm{~s}^{-1}$ and became more obvious under the hightemperature deformation conditions $\left(550{ }^{\circ} \mathrm{C}\right.$ at $0.01-0.001 \mathrm{~s}^{-1}$, Fig. $5 \mathrm{~b}$ and c). For example, for the deformation at $550{ }^{\circ} \mathrm{C}$ and $0.001 \mathrm{~s}^{-1}$, the flow stress of the $0.75 \mathrm{Mn}$ alloy decreased from $19.9 \mathrm{MPa}$ at the peak value to $9.5 \mathrm{MPa}$ at a strain of 0.75 , i.e., a decrease of $52 \%$. Under low $\mathrm{Z}$ deformation conditions, high deformation temperature and low strain rate provided higher mobility of boundaries and longer time for the energy accumulation, which results in enhanced dislocation annihilation and occurrence of DRV and DRX [37, 38] (Fig. 11므, Table 3). In this case, the dynamic softening greatly overcame the working and contributed to the decline of flow stress. Besides of the softening mechanisms, a rapid coarsening and dissolution of dispersoids was found during low $\mathrm{Z}$ deformation conditions. For example, after deformation at $550{ }^{\circ} \mathrm{C} / 0.001 \mathrm{~s}^{-1}$ condition, the dispersoids number density in $0.75 \mathrm{Mn}$ alloy dropped by $49 \%$, which was believed to be another factor contributing to flow stress decline. As a result, the large variation in flow stress with the progress of the deformation can affect the calculated $Q$.

Different approaches were employed for the calculation of $Q$. Although the peak flow stresses were commonly used $[19,20,24,33]$, the flow stresses at certain strains in the steady stage of deformation, e.g., 0.3 [32], 0.5 [42], and 0.8 [43], were also used as typical values to derive the $Q$ values in the literature. It is recognized that a complex microstructure evolution is involved during the hot deformation [44], which could strongly influence the flow stresses and thus the derived $Q$. In this study, the $Q$ values of the four alloys were also calculated using the flow stresses at different strains, as shown in Fig. 1015. The $Q$ values were the highest when were derived using the peak flow stresses. With the increase in strain from 0.3 to 0.75 , the $Q$ values significantly decreased, particularly for the three Mn-containing alloys. The decrease in $Q$ was smaller for the base alloy because the decrease in flow stress with the increase in strain under the low- $Z$ deformation conditions was not considerable (Fig. 5a). Fig. 10-15 shows that under all conditions, the differences in $Q$ between the base alloy (without dispersoids) and three dispersoid-containing alloys were considerable, indicating the strong effect of the dispersoids on the hot deformation resistance. However, with the increase in strain, the difference decreased and the differences in $Q$ between the three dispersoid-containing alloys vanished.

According to the constitutive analyses (section 3.3), it could be expected that a unique index $Q$ could be used to compare the difficulty levels of hot deformation of different chemical compositions or different microstructures. However, the results reveal that $Q$ is not constant and that considerably depends on the hot deformation conditions, because the flow stress often changes with the progress of the deformation. 
Therefore, it is not always simple to assess the hot workabilities of different aluminum materials using only $Q$. Shi et al. [24] reported that $Q$ mainly reflected the free-energy barrier to dislocation movement, which was affected by the deformation temperature and strain. In recent years, the concept of activation energy mapping was explored instead of treating $Q$ as a constant to study the hot workabilities of aluminum alloys $[25,45,46]$.

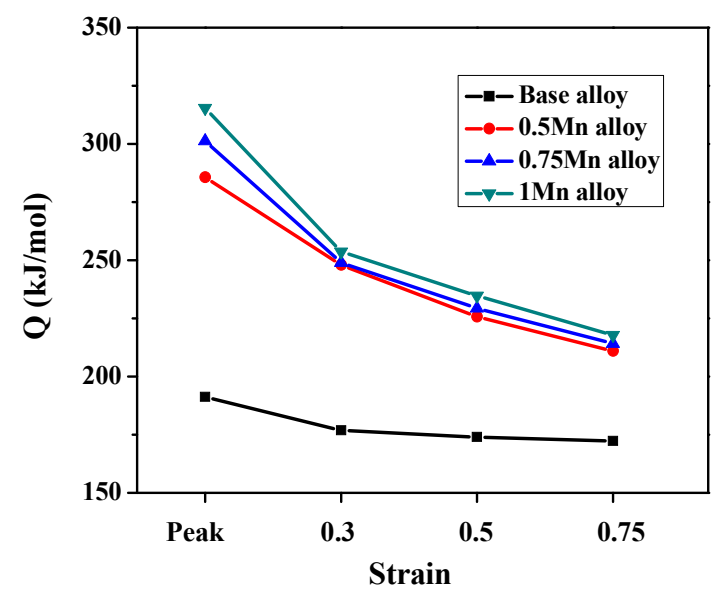

Fig. 10-15 Variation of the activation energies $Q$ of experimental alloys with deformation strain.

\section{Conclusions}

1. Upon treatment at the low homogenization temperature of $450{ }^{\circ} \mathrm{C}$ for $6 \mathrm{~h}$, large numbers of $\alpha-\mathrm{Al}(\mathrm{FeMn}) \mathrm{Si}$ dispersoids precipitated and were retained in the microstructures of the Mn-containing 6082 aluminum alloys. With an increase in Mn content, the number density of dispersoids increased, whereas the equivalent diameter was almost unchanged.

2. With the addition of $0.5 \%$ of $\mathrm{Mn}$, the peak flow stress significantly increased owing to the strong strengthening effect of the dispersoids, compared to the case of the base alloy without dispersoids. With a further increase in the Mn content from 0.5 to $1 \%$, the peak flow stress increased moderately.

3. The material constants and activation energies for hot deformation were calculated using the hyperbolic-sine constitutive equation and experimental peak flow stress data. The activation energies for hot deformation of the 6082 alloys considerably increased from $191.2 \mathrm{~kJ} / \mathrm{mol}$ for the base alloy to $285.6 \mathrm{~kJ} / \mathrm{mol}$ for the alloy containing $0.5 \%$ of $\mathrm{Mn}$. With a further increase in the Mn content, the activation energy increased moderately to 301.2 and $315.4 \mathrm{~kJ} / \mathrm{mol}$ for $0.75 \mathrm{Mn}$ and $1 \mathrm{Mn}$ alloys respectively. 
4. The addition of $\mathrm{Mn}$ in the 6082 alloy promoted the retardation of DRV and inhibition of DRX during the hot deformation owing to the strong pinning effect of the Mn-containing dispersoids on the dislocation slips and subgrain rotations.

5. In the Mn-containing alloys, the flow stresses largely decreased with an increase in strain under the relatively low $Z$ deformation conditions after reaching the peak flow stresses. Therefore, the derived activation energies significantly decreased with an increase in strain, showing the dependence of the activation energy on the deformation conditions.

\section{Acknowledgements}

The authors would like to acknowledge the financial support from the Natural Sciences and Engineering Research Council of Canada (NSERC) and Rio Tinto Aluminum, through the NSERC Industry Research Chair in Metallurgy of Aluminum Transformation at the University of Quebec at Chicoutimi.

\section{References}

[1] Y.J. Li, A.M.F. Muggerud, A. Olsen, T. Furu, Acta Mater. 60 (2012) 1004-1014.

[2] K. Liu, X.-G. Chen, Materials and Design, 84 (2015) 340-350.

[3] A.R. Farkoosh, X.-G. Chen, M. Pekguleryuz, Mater. Sci. Eng. A 620 (2015) 181189.

[4] D. H. Lee, J. H. Park, S. W. Nam, Mater. Sci. Technol 15 (1999) 450-455.

[5] Z. Li, Z. Zhang, X.-G. Chen, Mater. Sci. Eng. A 708 (2017) 383-394.

[6] K. Liu, H. Ma, X.-G. Chen, J. Alloy Comp. 694 (2017) 354-365.

[7] Y. J. Li, W. Z. Zhang, K. Marthinsen, Acta Mater. 60 (2012) 5963-5974.

[8] R. Zhang, Y. Zhang, Y. Yan, S. Thomas, C. H. J. Davies, N. Birbilis, Corros. Sci. 126 (2017) 324-333.

[9] A.R. Farkoosh, X.-G. Chen, M. Pekguleryuz, Mater. Sci. Eng. A 627 (2015) 127138.

[10] K. Liu, X.-G. Chen, J. Mater. Res. 33 (2018) 3430-3438.

[11] Y. Birol, J. Mater. Process Technol. 173 (2006) 84-91.

[12] L. Lodgaard, N. Ryum, Precipitation of dispersoids containing Mn and/or Cr in Al-Mg-Si alloys, Mater. Sci. Eng. A 283 (2000) 144-152.

[13] C. Liu, PhD thesis, The University of British Columbia (2017) 74-92

[14] C. Liu, Q. Du, N. Parson, W. Poole, Scripta Mater. 152 (2018) 59-63.

[15] C. Li, Master thesis, University of Quebec at Chicoutimi (2018), 53-63.

[16] H. J. McQueen, S. Spigarelli, M. Kassner, E. Evagelista, Hot Deformation and Processing of Aluminum Alloys, CRC Press, Bradenton, FL, (2011) 87-233.

[17] M. Shakiba, N. Parson, X.-G. Chen, Mater. Sci. Eng. A 619 (2014) 180-189.

[18] G. Avramovic-Cingara, D.D. Perovic, H. J. McQueen, Metall. Mater. Trans. A 27 
(1996) 3478.

[19] C. Shi, X.-G. Chen, Mater. Sci. Eng. A 613 (2014) A 596 (2014) 183-193.

[20] C. Shi, X.-G. Chen, Mater. Sci. Eng. A 613 (2014) A 613 (2014) 91-102.

[21] C. Sellars, W. McTegart, Mem. Sci. Rev. Met. 63 (1966) 731-746.

[22] M. Shakiba, N. Parson, X.-G. Chen, Mater. Sci. Eng. A 636 (2015) 572-581.

[23] B. Zhang, T. Baker, J. Mater. Proc. Tech. (2004) 153-154, 881-885.

[24] C. Shi, W. Mao, X.-G. Chen, Mater. Sci. Eng. A 571 (2013) 83-91.

[25] Peng, X., Su, W., Xiao, D. and Xu, G., JOM 70 (2018) 993-999.

[26] W. Geertruyden, W. Misiolek, P. Wang, Mater. Sci. Eng. A 419 (2006) 105-114.

[27] R. Kaibyshev, O. Sitdikov, A. Goloborodko, Mater. Sci. Eng. A 344 (2003) 348356.

[28] S. Gourdet, F. Montheillet, Mater. Sci. Eng. A 283 (2000) 274-288

[29] H.E. Hu, L. Zhen, L. Yang, W.Z. Shao, B.Y. Zhang, Mater. Sci. Eng. A 488 (2008) 64.

[30] R. Hu, T. Ogura, H. Tezuka, T. Sato and Q. Liu, J. Mater. Sci. Technol. 26(3) (2010) 237-243.

[31] D. Samantaray, S. Mandal, C. Phaniraj, A. Bhaduri, Mater. Sci. Eng. A 528 (2011) 8565.

[32] H. Liao, Y. Wu, K. Zhou, J. Yang, Mater. Des. 65 (2015) 1091-1099.

[33] S. Spigarelli, E. Evangelista, H. J. McQueen, Scr. Mater. 49 (2003) 179-183

[34] S. Gourdet, E.V. Konopleva, H. J. McQueen, F. Montheillet, Mat. Sci. Forum 217 (1996) 441-446.

[35] F. J. Humphreys, M. Hatherly, 2nd ed., Elsevier, Oxford (2004) 169-213, 415-450.

[36] H. J. McQueen, W.A. Wong, and J. J. Jonas, Can. J. Phys. 45 (1967) 25-1234.

[37] J. J. Jonas, D. R. Axelrad, J. L. Uvira, Trans. Jpn. Inst. Met. 9 (1968) 257-267.

[38] S. B. Brown, K. H. Kim, L. Anand, Int. J. Plast. 5 (1989) 95-130.

[39] H. J. McQueen, J. E. Hockett, Met. Trans. 1 (1970) 2997-3004.

[40] G. Avramovic-Cingara, D. D. Perovic, H. J. McQueen, Metall. Mater. Trans. A 27 (1996) 3478.

[41] D. H. Lee, J. H. Park, S.W. Nam, Mater. Sci. Technol. 15 (1999) 450-455.

[42] X. Kai, C. Chen, X. Sun, C. Wang, Y. Zhao, Mater. Des. 90 (2016) 1151-1158.

[43] M. Shakiba, N. Parson, X.-G. Chen, J. Mater. Eng. Perform. 24 (2015) 405-415.

[44] Q. Yang, D. Yang, Z. Zhang, L. Cao, X. Wu, G. Huang, Q. Liu, Trans. Nonferrous Met. Soc. China 26 (2016) 649-657.

[45] C. Shi, X.-G. Chen, Mater. Sci. Eng. A 650 (2016) 97-209.

[46] S. Wang, L. G. Hou, J. R. Luo, J. S. Zhang, L. Z. Zhuang. J. Mater. Process. Tech. 225 (2015) 110-121. 